\title{
Effect the Accuracy of Benchmarks to Establish of the Determination of Geodetic Network
}

\author{
Elżbieta Jasińska, Edward Preweda \\ AGH University of Science and Technology, 30 Mickiewicza Av. pav. C-4, 30-059 Krakow, Poland
}

\begin{abstract}
In classical applications of parametric method to compensate the coordinates of geodetic networks is usually assumed to establish faultless points. The object of estimation parameters, the coordinates of points are determined by observations which mediate appointment of unknowns. References points can have larger standard deviations than the accuracy of observations. This is the results of the advances in technology. If it is necessary to obtain the coordinates of the height accuracy freely alignment is often used, taking for example the coordinates of one point and the azimuth direction of the flat networks or the level of only one point from network leveling. This simplified solution is justified when it is important to get internal network precision because we get rid of the errors in this way to benchmark point. This is not the exact solution.

In the case of having the knowledge of variance-covariance matrix of benchmark points, it should be reflected in calculation. In the case of benchmarks, which amount was set many years ago, generally covariance are not known. In this case, alignment it is still possible, it can be based on the variance, which can be determined, for example, on the altitude network class. Benchmark points are considered establish in this case as the observations and unknowns simultaneously. They shall be the subject to appointment and are treated as pseudo-observations.

This article is an example of comparison between network adjustment which included level marks standard deviation and the other one freely alignment and assumptions inerrancy establish points. Convenient extension of the of parametric method was proposed, where the notion of observation equations for the point (coordinate) was interposed.
\end{abstract}

Keywords: Benchmarks; Geodetic Network; freely alignment.

\section{Introduction}

In surveying practice very often benchmark points are threaten as flawless. To avoid this problem, when observation are saddled with standard deviations, often alignment is performed on the basis of one benchmark. The main issue is that choice of selected benchmark obtain to different appointed points heights.

Stochastic Model [1] network alignment has the form

$$
\operatorname{Cov}(\mathrm{L}, \mathrm{X})==\left[\begin{array}{c:c}
\operatorname{Cov}(\mathrm{L}) & \mathbf{0} \\
\hdashline \mathbf{0} & \operatorname{Cov}(\mathrm{X})
\end{array}\right]
$$

Matrix $\operatorname{Cov}(\mathrm{L})$ for observations can be written down as diagonal matrix $\operatorname{Cov}(\hat{L})=\operatorname{diag}\left\{V\left(h_{i}\right)\right\}$. In the stochastic model covariance matrix $\operatorname{Cov}(\mathrm{X})$ altitude reference points can be approximated by the different models, for example:

$-\operatorname{Cov}(\hat{X})=\mathbf{0} \quad-$ the assumption of references points as a flawless,

$-\operatorname{Cov}(\hat{X})=\hat{\sigma}^{2} \mathbf{E} \quad$ - the assumption that height are equally accurate and uncorrelated,

- $\operatorname{Cov}(\hat{X})=\hat{\sigma}^{2} \mathbf{D} \quad$ - the assumption that references points are uncorrelated but not equally accurate,

- $\operatorname{Cov}_{(i, j)}(\hat{X})=\hat{\sigma}^{2} \mathbf{D}_{(i, i)}$ - consideration of only one establishing benchmark with known variance,

- $\operatorname{Cov}(\hat{X})=\hat{\sigma}^{2} \mathbf{W}^{(i, i)}$ - the model takes into account the full covariance matrix for reference points.

Taking into account the strict alignment, you should definitely use the last model, as far as is known, full covariance matrix for references points. The differences that may occur during the network adjustment altitude to references points with lower accuracy than the measurement accuracy was demonstrated, on the basis of calculations in eight different solutions. In

Corresponding author: Edward Preweda. E-mail address: edward.preweda@agh.edu.pl

http://dx.doi.org/10.3846/enviro.2014.212

(C) 2014 The Authors. Published by VGTU Press. This is an open-access article distributed under the terms of the Creative Commons Attribution License, which permits unrestricted use, distribution, and reproduction in any medium, provided the original author and source are credited. 
the second step, network was adjustment, and their points were used for the experiment. The calculation results are documented and presented in section 3 .

\section{The based height network alignment}

The based network (Fig. 1) contains one accurate benchmark and three determined points. Assumed accuracy of the measurement order of $1 \mathrm{~cm}$. In step 3, with reference to benchmarks A, B, C will be carried out in further considerations.

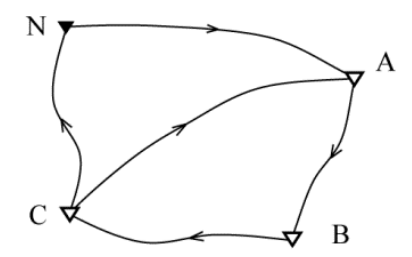

Fig. 1. A sketch of the network co-operated to one point

The height of benchmark is equal $Z_{N}=100,000 \mathrm{~m}$. The values of measurements $\mathrm{h}$ and distance $\mathrm{L}$ are given below:

$$
\begin{array}{ll}
\mathrm{h}_{\mathrm{N}-\mathrm{A}}=-1,000 m & \mathrm{~L}_{\mathrm{N}-\mathrm{A}}=1,6 k m \\
\mathrm{~h}_{\mathrm{A}-\mathrm{B}}=1,980 m & \mathrm{~L}_{\mathrm{A}-\mathrm{B}}=2,0 k m \\
\mathrm{~h}_{\mathrm{B}-\mathrm{C}}=-0,530 m & \mathrm{~L}_{\mathrm{B}-\mathrm{C}}=1,0 \mathrm{~km} \\
\mathrm{~h}_{\mathrm{C}-\mathrm{N}}=-0,480 m & \mathrm{~L}_{\mathrm{C}-\mathrm{N}}=1,8 k m \\
\mathrm{~h}_{\mathrm{C}-\mathrm{A}}=-1,480 m & \mathrm{~L}_{\mathrm{C}-\mathrm{A}}=1,4 k m
\end{array}
$$

As a result of strict offset height network using the method of least squares was obtained the following values of the estimated parameters:

$$
\begin{aligned}
& \hat{Z}_{A}=98,0035 m \\
& \hat{Z}_{B}=100,9985 m \\
& \hat{Z}_{C}=100,4761 m
\end{aligned} \quad \hat{\sigma}_{o}=10,6 \mathrm{~mm} / \mathrm{km} \quad \operatorname{Cov}(\hat{Z})=\left[\begin{array}{rrr}
114,10 & 87,74 & 74,56 \\
87,74 & 173,88 & 104,22 \\
87,74 & 87,74 & 119,04
\end{array}\right] \mathrm{mm}^{2} \quad \begin{aligned}
& \hat{\sigma}_{Z_{A}}= \pm 10,7 \mathrm{~mm} \\
& \hat{\sigma}_{Z_{B}}= \pm 13,2 \mathrm{~mm} \\
& \hat{\sigma}_{Z_{C}}= \pm 10,9 \mathrm{~mm}
\end{aligned}
$$

$$
\begin{aligned}
& \mathrm{v}_{\mathrm{N}-\mathrm{A}}=3,5 \mathrm{~mm} \quad \hat{\mathrm{h}}_{\mathrm{N}-\mathrm{A}}=-0,9965 \mathrm{~m} \\
& \mathrm{v}_{\mathrm{A}-\mathrm{B}}=15,0 \mathrm{~mm} \quad \hat{\mathrm{h}}_{\mathrm{A}-\mathrm{B}}=1,9950 \mathrm{~m} \\
& \mathrm{v}_{\mathrm{B}-\mathrm{C}}=7,5 \mathrm{~mm} \quad \hat{\mathrm{h}}_{\mathrm{B}-\mathrm{C}}=-0,5225 \mathrm{~m} \\
& \mathrm{v}_{\mathrm{C}-\mathrm{N}}=3,9 \mathrm{~mm} \quad \hat{\mathrm{h}}_{\mathrm{C}-\mathrm{N}}=-0,4761 \mathrm{~m} \\
& \mathrm{v}_{\mathrm{C}-\mathrm{A}}=7,5 \mathrm{~mm} \quad \hat{\mathrm{h}}_{\mathrm{C}-\mathrm{A}}=-1,4725 \mathrm{~m} \\
& \operatorname{Cov}(\hat{\mathrm{h}})=\left[\begin{array}{ccccc}
114,10 & -26,36 & -13,18 & -74,56 & 39,54 \\
-26,36 & 112,50 & -56,49 & -29,65 & -56,01 \\
-13,18 & -56,49 & 84,49 & -14,83 & -28,01 \\
-74,56 & -29,65 & -14,83 & 119,04 & 44,48 \\
39,54 & -56,01 & -28,01 & 44,48 & 84,02
\end{array}\right] \mathrm{mm}^{2} \quad \begin{array}{l}
\hat{\sigma}_{h_{N-A}}= \pm 10,7 \mathrm{~mm} \\
\hat{\sigma}_{h_{N-A}}= \pm 10,6 \mathrm{~mm} \\
\hat{\sigma}_{h_{N-A}}= \pm 9,2 \mathrm{~mm} \\
\hat{\sigma}_{h_{N-A}}= \pm 10,9 \mathrm{~mm} \\
\hat{\sigma}_{h_{N-A}}= \pm 9,2 \mathrm{~mm}
\end{array}
\end{aligned}
$$

\section{Alignment height network established to three benchmarks}

In the remainder of the alignment problem, let consider a network established to benchmarks A, B, C, for which is known the height and covariance matrix set in step 2. Nine hills were measurement. This time, the accuracy of measurement is at millimeter level. 


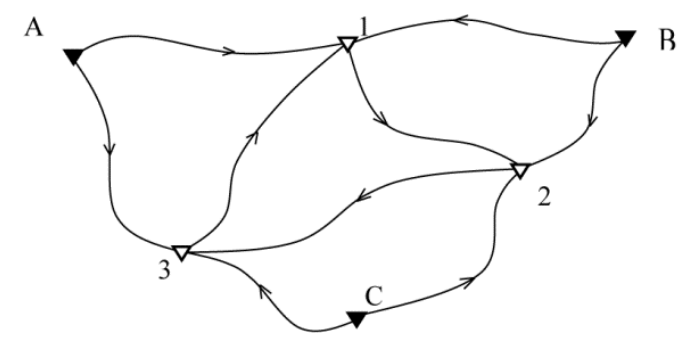

Fig. 2. A sketch of the network co-operated to three points

Measured values of hills $\mathrm{h}$ and $\mathrm{L}$ string length are given below:

$\begin{array}{rlrl}\mathrm{h}_{\mathrm{A}-1} & =1,500 m & \mathrm{~L}_{\mathrm{A}-1}=1,6 k m \\ \mathrm{~h}_{\mathrm{B}-2}=1,999 m & \mathrm{~L}_{\mathrm{B}-2}=2,0 k m \\ \mathrm{~h}_{\mathrm{C}-3}=-0,505 m & \mathrm{~L}_{\mathrm{C}-3}=1,0 k m \\ \mathrm{~h}_{1-2}=2,509 m & \mathrm{~L}_{1-2}=1,8 k m \\ \mathrm{~h}_{2-3}=-3,037 m & \mathrm{~L}_{2-3}=1,4 k m \\ \mathrm{~h}_{3-1}=0,526 m & \mathrm{~L}_{3-1}=1,8 k m \\ \mathrm{~h}_{\mathrm{A}-3}=0,970 m & \mathrm{~L}_{\mathrm{A}-3}=1,2 k m \\ \mathrm{~h}_{\mathrm{B}-1}=-0,506 m & \mathrm{~L}_{\mathrm{B}-1}=1,4 k m \\ \mathrm{~h}_{\mathrm{C}-2}=2,530 m & \mathrm{~L}_{\mathrm{C}-2}=1,6 k m\end{array}$

Let consider the alignment of the network according to eight variants that apply in practice.

3.1. Option 1-zero standard deviations of benchmarks $A, B, C$

On such assumptions the estimated value of the following parameters is equal: $\hat{\sigma}_{o}=5,7 \mathrm{~mm} / \mathrm{km}$

$$
\begin{aligned}
& \hat{Z}_{1}=100,5047 \mathrm{~m} \\
& \hat{Z}_{2}=103,0037 \mathrm{~m} \\
& \hat{Z}_{3}=99,9722 \mathrm{~m}
\end{aligned} \quad \operatorname{Cov}(\hat{Z})=\left[\begin{array}{rrr}
15,18 & 4,65 & 3,79 \\
4,65 & 16,00 & 4,51 \\
3,79 & 4,51 & 12,19
\end{array}\right] \mathrm{mm}^{2} \quad \begin{aligned}
& \hat{\sigma}_{Z_{1}}= \pm 10,7 \mathrm{~mm} \\
& \hat{\sigma}_{Z_{2}}= \pm 13,2 \mathrm{~mm} \\
& \hat{\sigma}_{Z_{3}}= \pm 10,9 \mathrm{~mm}
\end{aligned}
$$

Despite the accuracy of measurements at millimeter, we get the significant value of the standard deviation of adjustment height, which is the result of benchmarks inaccuracy. Random deviation $\mathrm{v}$, and standard deviations of elevations also greatly exceed the accuracy of the measurements.

$\begin{array}{rrll}\mathrm{v}_{\mathrm{A}-1}= & 1,2 \mathrm{~mm} & \hat{\mathrm{h}}_{\mathrm{A}-1}=1,5012 \mathrm{~m} & \hat{\sigma}_{h_{A-1}}= \pm 3,9 \mathrm{~mm} \\ \mathrm{v}_{\mathrm{B}-2}= & 6,2 \mathrm{~mm} & \hat{\mathrm{h}}_{\mathrm{B}-2}=2,0052 \mathrm{~m} & \hat{\sigma}_{h_{B-2}}= \pm 4,0 \mathrm{~mm} \\ \mathrm{v}_{\mathrm{C}-3}= & 1,1 \mathrm{~mm} & \hat{\mathrm{h}}_{\mathrm{C}-3}=-0,5039 \mathrm{~m} & \hat{\sigma}_{h_{C-3}}= \pm 3,5 \mathrm{~mm} \\ \mathrm{v}_{1-2}=-10,0 \mathrm{~mm} & \hat{\mathrm{h}}_{\mathrm{h}-2}=2,4990 \mathrm{~m} & \hat{\sigma}_{h_{1-2}}= \pm 4,7 \mathrm{~mm} \\ \mathrm{v}_{2-3}= & 5,4 \mathrm{~mm} & \hat{\mathrm{h}}_{2-3}=-3,0316 \mathrm{~m} & \hat{\sigma}_{h_{2-3}}= \pm 4,4 \mathrm{~mm} \\ \mathrm{v}_{3-1}= & 6,6 \mathrm{~mm} & \hat{\mathrm{h}}_{3-1}=0,5326 \mathrm{~m} & \hat{\sigma}_{h_{3-1}}= \pm 4,4 \mathrm{~mm} \\ \mathrm{v}_{\mathrm{A}-3}=-1,3 \mathrm{~mm} & \hat{\mathrm{h}}_{\mathrm{A}-3}=0,9687 \mathrm{~m} & \hat{\sigma}_{h_{A-3}}= \pm 3,5 \mathrm{~mm} \\ \mathrm{v}_{\mathrm{B}-1}= & 9,7 \mathrm{~mm} & \hat{\mathrm{h}}_{\mathrm{B}-1}=-0,4963 \mathrm{~m} & \hat{\sigma}_{h_{B-1}}= \pm 3,9 \mathrm{~mm} \\ \mathrm{v}_{\mathrm{C}-2}=-2,3 \mathrm{~mm} & \hat{\mathrm{h}}_{\mathrm{C}-2}=2,5277 \mathrm{~m} & \hat{\sigma}_{h_{C-2}}= \pm 4,0 \mathrm{~mm}\end{array}$

Presented at that point resolved should not be applied in practice.

\subsection{Option 2-standard deviation of benchmark $A$ is taken into account}

For this variant is obtained estimators do the following parameter values: $\hat{\sigma}_{o}=1,4 \mathrm{~mm} / \mathrm{km}$ 


$\begin{aligned} & \hat{Z}_{1}=100,5023 m \\ & \hat{Z}_{2}=103,0104 m \\ & \hat{Z}_{3}=99,9744 m \\ & \hat{Z}_{B}=101,0096 m \\ & \hat{Z}_{C}=100,4798 m\end{aligned} \quad \operatorname{Cov}(\hat{Z})=\left[\begin{array}{ccccc}1,83 & 1,37 & 1,01 & 1,64 & 1,15 \\ /-/ & 2,38 & 1,36 & 1,79 & 1,75 \\ /-/ & /-/ & 1,63 & 1,16 & 1,52 \\ /-/ & /-/ & /-/ & 3,34 & 1,40 \\ /-/ & /-/ & /-/ & /-/ & 2,83\end{array}\right] \mathrm{mm}^{2} \quad \begin{aligned} & \hat{\sigma}_{Z_{1}}= \pm 1,4 \mathrm{~mm} \\ & \end{aligned} \quad \begin{aligned} & \hat{\sigma}_{Z_{2}}= \pm 1,5 \mathrm{~mm} \\ & \hat{\sigma}_{Z_{3}}= \pm 1,3 \mathrm{~mm} \\ & \hat{\sigma}_{Z_{B}}= \pm 1,1 \mathrm{~mm} \\ & \hat{\sigma}_{Z_{C}}= \pm 1,2 \mathrm{~mm}\end{aligned}$

Random deviation v, adjustment elevations $\hat{\mathrm{h}}$ and their standard deviations $\hat{\sigma}_{h}$ are of the form:

$\begin{array}{llll}\mathrm{v}_{\mathrm{A}-1}=-1,2 \mathrm{~mm} & \hat{\mathrm{h}}_{\mathrm{A}-1}=1,4988 \mathrm{~m} & \hat{\sigma}_{h_{A-1}}= \pm 1,4 \mathrm{~mm} \\ \mathrm{v}_{\mathrm{B}-2}=1,8 \mathrm{~mm} & \hat{\mathrm{h}}_{\mathrm{B}-2}=2,0008 \mathrm{~m} & \hat{\sigma}_{h_{B-2}}= \pm 1,5 \mathrm{~mm} \\ \mathrm{v}_{\mathrm{C}-3}=-0,4 \mathrm{~mm} & \hat{\mathrm{h}}_{\mathrm{C}-3}=-0,5054 \mathrm{~m} & \hat{\sigma}_{h_{C-3}}= \pm 1,2 \mathrm{~mm} \\ \mathrm{v}_{1-2}=-1,0 \mathrm{~mm} & \hat{\mathrm{h}}_{\mathrm{L}-2}=2,5080 \mathrm{~m} & \hat{\sigma}_{h_{1-2}}= \pm 1,2 \mathrm{~mm} \\ \mathrm{v}_{2-3}=1,0 \mathrm{~mm} & \hat{\mathrm{h}}_{2-3}=-3,0360 \mathrm{~m} & \hat{\sigma}_{h_{2-3}}= \pm 1,1 \mathrm{~mm} \\ \mathrm{v}_{3-1}=2,0 \mathrm{~mm} & \hat{\mathrm{h}}_{3-1}=0,5280 \mathrm{~m} & \hat{\sigma}_{h_{3-1}}= \pm 1,2 \mathrm{~mm} \\ \mathrm{v}_{\mathrm{A}-3}=0,9 \mathrm{~mm} & \hat{\mathrm{h}}_{\mathrm{A}-3}=0,9709 \mathrm{~m} & \hat{\sigma}_{h_{A-3}}= \pm 1,3 \mathrm{~mm} \\ \mathrm{v}_{\mathrm{B}-1}=-1,2 \mathrm{~mm} & \hat{\mathrm{h}}_{\mathrm{B}-1}=-0,5072 \mathrm{~m} & \hat{\sigma}_{h_{B-1}}= \pm 1,4 \mathrm{~mm} \\ \mathrm{v}_{\mathrm{C}-2}=0,6 \mathrm{~mm} & \hat{\mathrm{h}}_{\mathrm{C}-2}=2,5306 \mathrm{~m} & \hat{\sigma}_{h_{C-2}}= \pm 1,3 \mathrm{~mm}\end{array}$

This solution is free from inaccuracy of benchmarks, however, is not clear. In truth, the value of the standard deviation only affects the accuracy of the measurements, however, in the case of references to another benchmark, other values of the adjustment height playing field.

\subsection{Option 3- zero standard deviation for $B$}

As a result of strict compensation is received: $\hat{\sigma}_{o}=1,4 \mathrm{~mm} / \mathrm{km}$

$$
\begin{aligned}
& \hat{Z}_{1}=100,4913 m \\
& \hat{Z}_{2}=102,9993 m \\
& \hat{Z}_{3}=99,9633 m \\
& \hat{Z}_{A}=98,9925 m \\
& \hat{Z}_{C}=100,4687 m
\end{aligned} \quad \operatorname{Cov}(\hat{Z})=\left[\begin{array}{rrrrr}
1,89 & 1,28 & 1,55 & 1,70 & 1,45 \\
/-/ & 2,15 & 1,75 & 1,55 & 1,90 \\
/-/ & /-/ & 2,65 & 2,18 & 2,31 \\
/-/ & /-/ & /-/ & 3,34 & 1,94 \\
/ / / & /-/ & /-/ & /-/ & 3,37
\end{array}\right] \mathrm{mm}^{2} \quad \begin{aligned}
& \hat{\sigma}_{Z_{1}}= \pm 1,4 \mathrm{~mm} \\
& \hat{\sigma}_{Z_{2}}= \pm 1,5 \mathrm{~mm} \\
& \hat{\sigma}_{Z_{3}}= \pm 1,6 \mathrm{~mm} \\
& \hat{\sigma}_{Z_{A}}= \pm 1,5 \mathrm{~mm} \\
& \hat{\sigma}_{Z_{C}}= \pm 1,5 \mathrm{~mm}
\end{aligned}
$$

Naturally random deviation $\mathrm{v}$, aligned elevations $\hat{\mathrm{h}}$ and their standard deviations $\hat{\sigma}_{h}$ are the same as in the previous option (option 2).

\subsection{Option 4-zero standard deviation for $C$}

As a result of strict compensation is received: $\hat{\sigma}_{o}=1,4 \mathrm{~mm} / \mathrm{km}$

$$
\begin{aligned}
& \hat{Z}_{1}=100,4986 \mathrm{~m} \\
& \hat{Z}_{2}=103,0067 \mathrm{~m} \\
& \hat{Z}_{3}=99,9707 \mathrm{~m} \\
& \hat{Z}_{A}=98,9998 \mathrm{~m} \\
& \hat{Z}_{B}=101,0059 \mathrm{~m}
\end{aligned} \quad \operatorname{Cov}(\hat{Z})=\left[\begin{array}{rrrrr}
2,36 & 1,30 & 1,17 & 1,68 & 1,93 \\
/-/ & 1,71 & 0,92 & 1,08 & 1,47 \\
/-/ & /-/ & 1,41 & 1,31 & 1,07 \\
/-/ & /-/ & /-/ & 2,83 & 1,44 \\
/-/ & /-/ & /-/ & /-/ & 3,37
\end{array}\right] \mathrm{mm}^{2} \quad \begin{aligned}
& \hat{\sigma}_{Z_{1}}= \pm 1,5 \mathrm{~mm} \\
& \\
& \quad \hat{\sigma}_{Z_{2}}= \pm 1,3 \mathrm{~mm} \\
& \hat{\sigma}_{Z_{3}}= \pm 1,2 \mathrm{~mm} \\
& \hat{\sigma}_{Z_{A}}= \pm 1,1 \mathrm{~mm} \\
& \hat{\sigma}_{Z_{B}}= \pm 1,0 \mathrm{~mm}
\end{aligned}
$$

Random deviation $\mathrm{v}$, aligned elevations $\hat{\mathrm{h}}$ and their standard deviations are the same as in the previous options $2 \mathrm{i} 3$.

\subsection{Option 5- benchmark A has known standard deviation, different than zero}

Sometimes, in order to obtain an assessment of the accuracy which include benchmarks standard deviation, it should be applied the solution to reference only to one point, but taking into account the standard deviation of the height of this point. 
In this case it is necessary to determine the weighting matrix, which has the form:

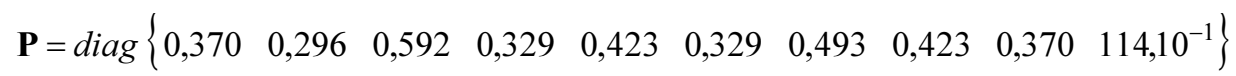

As a result of the compensation received by the method of least squares: $\hat{\sigma}_{o}=1,1$

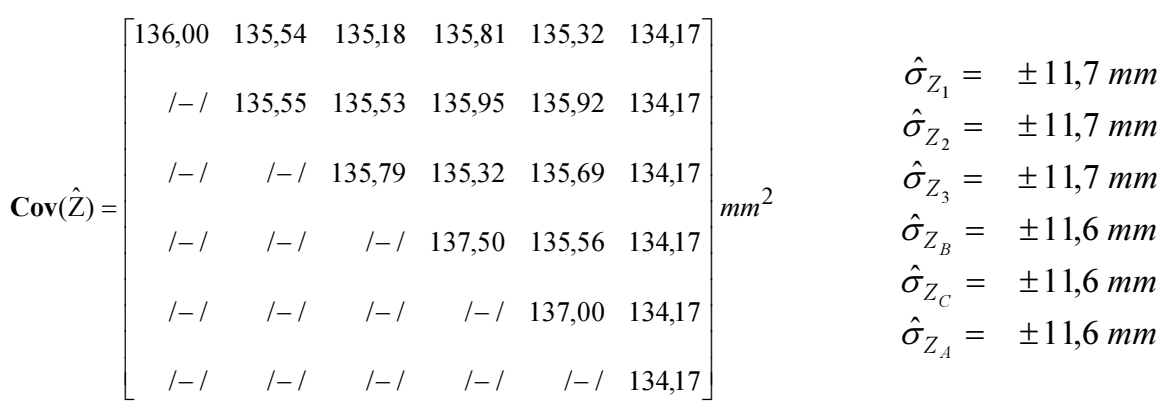

Standard deviation aligned elevations $\hat{\sigma}_{h}$ naturally are the same as in cases 2,3 i 4 .

3.6. Option 6- benchmark B has known standard deviation, different than zero

Wag matrix has the form:

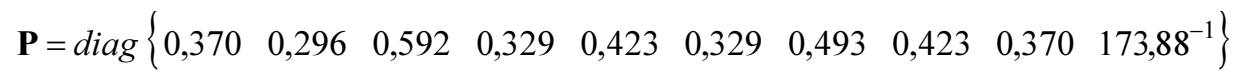

As a result of the compensation received by the method of least squares: $\hat{\sigma}_{o}=1,1$

$$
\operatorname{Cov}(\hat{Z})=\left[\begin{array}{rrrrrr}
203,35 & 205,74 & 206,02 & 206,16 & 205,91 & 204,46 \\
/-/ & 206,61 & 206,21 & 206,01 & 206,37 & 204,46 \\
I-/ & /-/ & 207,11 & 206,64 & 206,77 & 204,46 \\
I-/ & /-/ & /-/ & 207,80 & 206,40 & 204,46 \\
I-/ & /-/ & /-/ & /-/ & 207,84 & 204,46 \\
/-/ & /-/ & /-/ & /-/ & /-/ & 204,46
\end{array}\right] \mathrm{mm}^{2} \quad \begin{aligned}
& \hat{\sigma}_{Z_{1}}= \pm 14,4 \mathrm{~mm} \\
& \hat{\sigma}_{Z_{2}}= \pm 14,4 \mathrm{~mm} \\
& \hat{\sigma}_{Z_{3}}= \pm 14,4 \mathrm{~mm} \\
& \hat{\sigma}_{Z_{A}}= \pm 14,4 \mathrm{~mm} \\
& \hat{\sigma}_{Z_{C}}= \pm 14,4 \mathrm{~mm} \\
& \hat{\sigma}_{Z_{B}}= \pm 14,3 \mathrm{~mm}
\end{aligned}
$$

Similarly as in the previous example, the standard deviation of the elevations $\hat{\sigma}_{h}$ do not change compared to the variants 2 to 5 .

\subsection{Option 7- benchmark $C$ has known standard deviation, different than zero}

Wag matrix has the form:

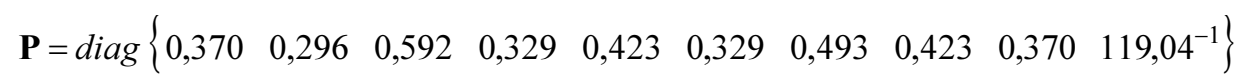

Putting together the results of the: $\hat{\sigma}_{o}=1,1$

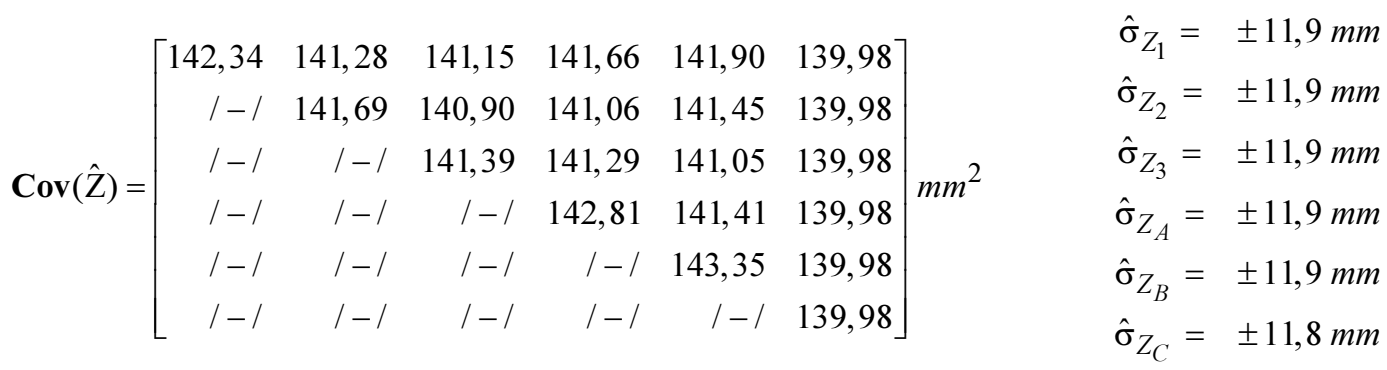

You may also find that the standard deviation of the hills (elevations) $\hat{\sigma}_{h}$ do not change. 


\subsection{Option 8- strict alignment, benchmarks A,B,C of known covariance matrix}

The matrix of coefficients of the observation equation is of the form:

\begin{tabular}{c|rrr:rrr} 
& $d Z_{1}$ & $d Z_{2}$ & $d Z_{3}$ & $d Z_{A}$ & $d Z_{B}$ & $d Z_{C}$ \\
\hline $\mathrm{v}_{\mathrm{h}_{\mathrm{A}-1}}$ & 1 & 0 & 0 & -1 & 0 & 0 \\
$\mathrm{v}_{\mathrm{h}_{\mathrm{B}-2}}$ & 0 & 1 & 0 & 0 & -1 & 0 \\
$\mathrm{v}_{\mathrm{h}_{\mathrm{C}-3}}$ & 0 & 0 & 1 & 0 & 0 & -1 \\
$\mathrm{v}_{\mathrm{h}_{1-2}}$ & 1 & -1 & 0 & 0 & 0 & 0 \\
$\mathrm{v}_{\mathrm{h}_{2-3}}$ & 0 & -1 & 1 & 0 & 0 & 0 \\
$\mathrm{v}_{\mathrm{h}_{3-1}}$ & 1 & 0 & -1 & 0 & 0 & 0 \\
$\mathrm{v}_{\mathrm{h}_{\mathrm{A}-3}}$ & 0 & 0 & 1 & -1 & 0 & 0 \\
$\mathrm{v}_{\mathrm{h}_{\mathrm{B}-1}}$ & 1 & 0 & 0 & 0 & -1 & 0 \\
$\mathrm{v}_{\mathrm{h}_{\mathrm{C}-2}}$ & 0 & 1 & 0 & 0 & 0 & -1 \\
\hline $\mathrm{v}_{\mathrm{Z}_{\mathrm{A}}}$ & 0 & 0 & 0 & 1 & 0 & 0 \\
$\mathrm{v}_{\mathrm{Z}_{\mathrm{B}}}$ & 0 & 0 & 0 & 0 & 1 & 0 \\
$\mathrm{v}_{\mathrm{Z}_{\mathrm{C}}}$ & 0 & 0 & 0 & 0 & 0 & 1
\end{tabular}

It's worth pointing out that taking into account the amount standard deviation of the benchmark, as observational equation stems from the fact that this height is also observed as well as unknown. Hence the observation as can be written as $\mathrm{v}_{\mathrm{Z}}=d Z$. The word free of this equation is 0 .

Variance-covariance matrix was written down in point 2. It adopted the following values:

$$
\operatorname{Cov}(\hat{A}, \hat{B}, \hat{C})=\left[\begin{array}{rrr}
114,10 & 87,74 & 74,56 \\
87,74 & 173,88 & 104,22 \\
87,74 & 87,74 & 119,04
\end{array}\right] \mathrm{mm}^{2}
$$

Wag matrix can be written in the form:

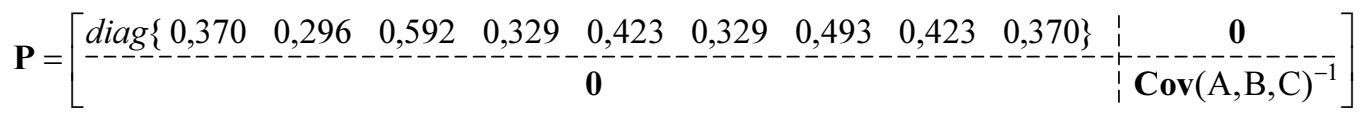

As a result of strict offset height network using the method of least squares obtained the following values of the estimated parameters: $\hat{\sigma}_{o}=0,98$

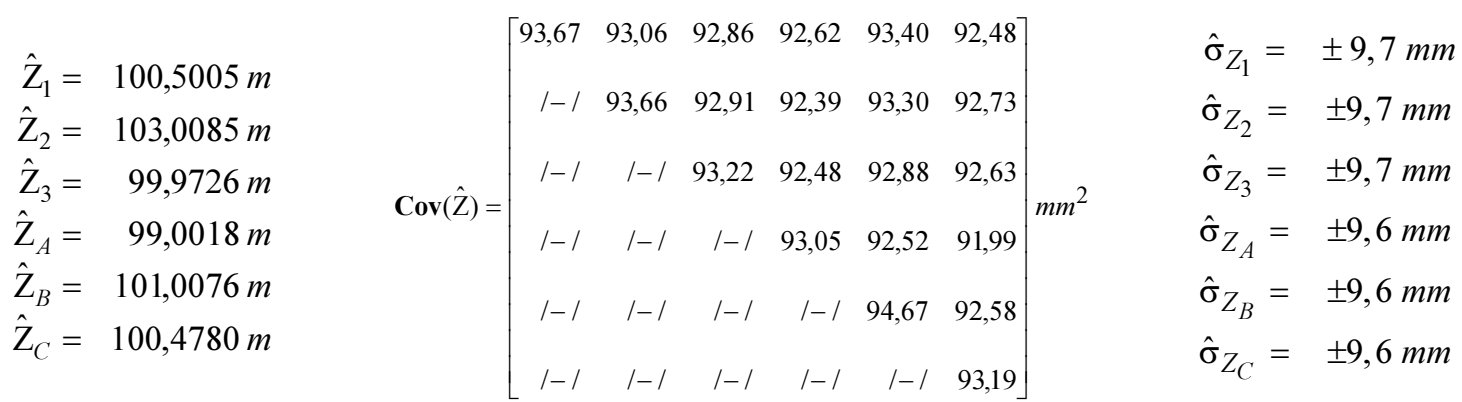

In this case, the value of the standard deviation affects both the accuracy of points to make and the accuracy of the measurement of the hills (elevations). Random deviation $\mathrm{v}$, aligned elevations $\hat{\mathrm{h}}$ and their standard deviations $\hat{\sigma}_{h}$ have the following values: 


$\begin{array}{rlrll}\mathrm{v}_{\mathrm{A}-1}=-1,3 \mathrm{~mm} & \hat{\mathrm{h}}_{\mathrm{A}-1}=1,4987 \mathrm{~m} & \hat{\sigma}_{h_{A-1}}= \pm 1,2 \mathrm{~mm} \\ \mathrm{v}_{\mathrm{B}-2}=1,9 \mathrm{~mm} & \hat{\mathrm{h}}_{\mathrm{B}-2}=2,0009 \mathrm{~m} & \hat{\sigma}_{h_{B-2}}= \pm 1,3 \mathrm{~mm} \\ \mathrm{v}_{\mathrm{C}-3}=-0,4 \mathrm{~mm} & \hat{\mathrm{h}}_{\mathrm{C}-3}=-0,5054 \mathrm{~m} & \hat{\sigma}_{h_{C-3}}= \pm 1,1 \mathrm{~mm} \\ \mathrm{v}_{1-2}=-1,0 \mathrm{~mm} & \hat{\mathrm{h}}_{1-2}=2,5080 \mathrm{~m} & \hat{\sigma}_{h_{1-2}}= \pm 1,1 \mathrm{~mm} \\ \mathrm{v}_{2-3}= & 1,1 \mathrm{~mm} & \hat{\mathrm{h}}_{2-3}=-3,0359 \mathrm{~m} & \hat{\sigma}_{h_{2-3}}= \pm 1,1 \mathrm{~mm} \\ \mathrm{v}_{3-1}=1,9 \mathrm{~mm} & \hat{\mathrm{h}}_{3-1}=1,5279 \mathrm{~m} & \hat{\sigma}_{h_{3-1}}= \pm 1,0 \mathrm{~mm} \\ \mathrm{v}_{\mathrm{A}-3}= & 0,8 \mathrm{~mm} & \hat{\mathrm{h}}_{\mathrm{A}-3}= & 0,9708 \mathrm{~m} & \hat{\sigma}_{h_{A-3}}= \pm 1,1 \mathrm{~mm} \\ \mathrm{v}_{\mathrm{B}-1}=-1,1 \mathrm{~mm} & \hat{\mathrm{h}}_{\mathrm{B}-1}=-0,5071 \mathrm{~m} & \hat{\sigma}_{h_{B-1}}= \pm 1,2 \mathrm{~mm} \\ \mathrm{v}_{\mathrm{C}-2}= & 0,5 \mathrm{~mm} & \hat{\mathrm{h}}_{\mathrm{C}-2}= & 2,5305 \mathrm{~m} & \hat{\sigma}_{h_{C-2}}= \pm 1,2 \mathrm{~mm} \\ \mathrm{v}_{\mathrm{Z}_{\mathrm{A}}}=-1,7 \mathrm{~mm} & \hat{\mathrm{Z}}_{\mathrm{A}}=99,0018 \mathrm{~m} & \hat{\sigma}_{Z_{A}}= \pm 9,6 \mathrm{~mm} \\ \mathrm{v}_{\mathrm{Z}_{\mathrm{B}}}= & 9,0 \mathrm{~mm} & \hat{\mathrm{Z}}_{\mathrm{B}}=101,0076 \mathrm{~m} & \hat{\sigma}_{Z_{B}}= \pm 9,7 \mathrm{~mm} \\ \mathrm{v}_{\mathrm{Z}_{\mathrm{C}}}= & 1,9 \mathrm{~mm} & \hat{\mathrm{Z}}_{\mathrm{C}}=100,4780 \mathrm{~m} & \hat{\sigma}_{Z_{C}}= \pm 9,7 \mathrm{~mm}\end{array}$

\section{Juxtaposition of the selected calculation results}

By analyzing the results of the calculations are carried out according to the variants of 1 to 8 , you will notice a distinct discrepancy between them. Generally it is assumed that the alignment of the network is carried out strictly. You need to put a clear question, what does the term mean? It's not only about the procedure in accordance with the method of least squares in the mathematical sense. The assumption that we accept at the outset, it is extremely important and decisive stage of the alignment of the results of the investigation. Table 1 summarizes the amount of height points with different variants, and in Table 2 differences between variants in comparison with option 8 .

Table 1. Statement of height points of 8 variants of calculation

\begin{tabular}{ccccccc}
\hline & ZA & ZB & ZC & Z1 & Z2 & Z3 \\
\hline Wariant 1 & $\mathbf{9 9 , 0 0 3 5}$ & $\mathbf{1 0 0 , 9 9 8 5}$ & $\mathbf{1 0 0 , 4 7 6 1}$ & 100,5047 & 103,0037 & 99,9722 \\
\hline Wariant 2 & $\mathbf{9 9 , 0 0 3 5}$ & 101,0096 & 100,4798 & 100,5023 & 103,0104 & 99,9744 \\
\hline Wariant 3 & 98,9925 & $\mathbf{1 0 0 , 9 9 8 5}$ & 100,4687 & 100,4913 & 102,9993 & 99,9633 \\
\hline Wariant 4 & 98,9925 & 100,9985 & $\mathbf{1 0 0 , 4 6 8 7}$ & 100,4986 & 103,0067 & 99,9707 \\
\hline Wariant 5 & $\mathbf{9 9 , 0 0 3 5}$ & 101,0096 & 100,4798 & 100,5023 & 103,0104 & 99,9744 \\
\hline Wariant 6 & 98,9925 & $\mathbf{1 0 1 , 0 0 9 6}$ & 100,4687 & 100,4913 & 102,9993 & 99,9633 \\
\hline Wariant 7 & 98,9998 & 101,0059 & $\mathbf{1 0 0 , 4 7 9 8}$ & 100,4986 & 103,0067 & 99,9707 \\
\hline Wariant 8 & $\mathbf{9 8 , 9 9 9 8}$ & $\mathbf{1 0 1 , 0 0 7 7}$ & $\mathbf{1 0 0 , 4 7 8 0}$ & 100,5005 & 103,0086 & 99,9726 \\
\hline
\end{tabular}

Table 2. Summary of differences in height comparison with the variant 8

\begin{tabular}{ccccccc}
\hline & $\mathrm{dzA}$ & $\mathrm{dZB}$ & $\mathrm{dZC}$ & $\mathrm{dZ1}$ & $\mathrm{dZ2}$ & $\mathrm{dZ3}$ \\
\hline Wariant 1 & $-3,7$ & 9,1 & 1,9 & $-4,2$ & 4,9 & 0,5 \\
\hline Wariant 2 & $-3,7$ & $-1,9$ & $-1,8$ & $-1,8$ & $-1,8$ & $-1,8$ \\
\hline Wariant 3 & 7,3 & 9,1 & 9,3 & 9,2 & 9,2 & 9,3 \\
\hline Wariant 4 & 7,3 & 9,1 & 9,3 & 1,9 & 1,9 & 1,9 \\
\hline Wariant 5 & $-3,7$ & $-1,9$ & $-1,8$ & $-1,8$ & $-1,8$ & $-1,8$ \\
\hline Wariant 6 & 7,3 & $-1,9$ & 9,3 & 9,2 & 9,2 & 9,3 \\
\hline Wariant 7 & 0,0 & 1,8 & $-1,8$ & 1,9 & 1,9 & 1,9 \\
\hline Wariant 8 & 0,0 & 0,0 & 0,0 & 0,0 & 0,0 & 0,0 \\
\hline
\end{tabular}

\section{Conclusions}

Widely known issue height network alignment by the method of least squares was intentionally imaged the various options to be adopted in practice. If we are should discuss the alignment, we must clearly and explicitly emphasize the importance of the variance-covariance matrix for the reference points. As far as sometimes variance are included, often at the same time equal values for reference points is assumed, as a rule, suppresses the value of covariance between the heights of different benchmarks. One of the basic difficulties of actually closely align network is the lack of information about the covariance matrix for the reference points. Such information simply is not stored in the archives of the relevant geodetic services. It is 
worth to be discussed following problem. We invest in the development of techniques in a modern and increasingly more accurate measuring equipment, often expensive. At the same time, we do not use fully the information that we receive as a result of measurement and alignment, information that are already and by the way, for free. Only problem is to properly archive and share this information.

\section{References}

[1] Preweda, E. 2013. Rachunek wyrównawczy $\Rightarrow$ modele statystyczne [Adjustment computations $\Rightarrow$ statistical models]. Kraków, Wyd. PROGRES, 2013 r., ISBN: 978-83-938093-0-1

[2] Rozporzqdzenie, MSWiA z 9 listopada 2011 w sprawie standardów technicznych wykonywania geodezyjnych pomiarów sytuacyjnych $i$ wysokościowych oraz opracowywania i przekazywania wyników tych pomiarów do państwowego zasobu geodezyjnego i kartograficznego (Dz. U. $\mathrm{z}$ 2011 r. Nr 263, poz. 1572)

[3] Rozporzqdzenie MAiC z dnia 14 lutego 2012 r. w sprawie osnów geodezyjnych, grawimetrycznych i magnetycznych (Dz U. z 2012 r. Poz. 352) 